\title{
Form-Finding, Architecture and Mathematics
}

\author{
Kim Williams ${ }^{1}$ (D) \\ Published online: 18 January 2022 \\ (c) Kim Williams Books, Turin 2022
}

\begin{abstract}
Editor-in-Chief Kim Williams discusses the versatility and range of tools used in exploring questions of form-finding both ancient and modern, and introduces the articles in Nexus Network Journal vol. 24no. 1 (2022).
\end{abstract}

Keywords Nexus Network Journal · Form-finding $\cdot$ Algorithmic modelling $\cdot$ Shape grammar $\cdot$ Grids $\cdot$ Justified plan graph analysis

The science of architectural design is fundamentally one of form-finding: architects seek to give shape to architectural solids (the envelope) and the voids (the space in which actions take place). In this issue of the $N N J$ various tools are presented to both create form and analyse forms already built. What makes this issue significant is the different ways in which the same tool is applied to different building types, in combination with the way the same research field can be explored by means of different tools. Thus, we see the shape grammar method used to respond to housing demands, but also to address acoustics; housing is studied by means of shape grammar, but also by means of justified plan graph analysis; examples of mosques are studied by means of grid analysis and by numerical models. Fields of mathematical study such as symmetry groups and topology also show their value here. The 'nexus' of architecture and mathematics is very much in evidence in this issue.

Our itinerary begins with examinations of housing. In both of these cases, residents' desires and demands play a role in determining form. First, in "A Combined Shape Grammar and Housing-Space Demand Approach: Customized Mass Housi ng Design in Rural Areas of the North China Plain" the research team of Jiang Wang, Bolun Zhao, Wei Fan, Yang Yang, and Jilong Zhao aim to provide a shape grammar-based method which can analyze design vocabularies and generate new solutions to rural housing. Their results show that an application of shape grammars

Kim Williams

kwb@kimwilliamsbooks.com

1 Kim Williams Books, Corso Regina Margherita, 72, 10153 Turin, Italy

Birkhäuser 
can effectively solve the problem of matching customized mass housing design with differentiated demands from users.

Lucia Elizondo, in "A Justified Plan Graph Analysis of Social Housing in Mexico (1974-2019): Spatial Transformations and Social Implications" looks at two different eras of housing, during which the needs and demands of residents changed. Her use of space syntax allows her to account for the embedding of residents' needs in the spaces they inhabit.

Two contributions in this issue look at questions involving movement in space. In the case of the research by Jonathan Dessi-Olive and Timothy Hsu, "A Simulation-Validated Shape Grammar for Architectural Acoustics", the motion involved is that of sound waves. By analyzing the way in which the interactions of invisible sound waves are impacted by visual design decisions, the authors were able to produce a shape grammar that can ultimately allow designers to create forms based on elements of acoustic theory and performance.

In the second paper about movement, staircases provide the possibility of vertical transition in space, while also offering rich sculptural possibilities. In "On the Topology of the Double Staircase", Andrew Witt and Iman Fayyad survey historical archetypes of the double staircase and present a topological taxonomy for the double staircase. This allows for both a rigorous formal classification and the exploration of the generative range of algorithmically produced double staircases. One example of their work graces the cover of this issue.

Four contributions in this issue, from researchers in four different areas of the world, examine issues of structural form-finding. The Indonesian team of Nabila Afif, Nur Zahrotunnisaa Zagi, Agus Hariyadi, and Annisa Putri Cinderakasih present "A Modular Interlocking Element for Material-Efficient Stereotomy Construction", in which their aim is to address the paradox, where customization produces efficient design yet inefficient fabrication. They do this by applying a parametric design approach and a rapid additive prototyping method in order to determine a clear workflow and optimized designs.

In "Algorithmic Modelling as a Key Tool for Ribbed Vault Geometry", the Italian team of Vincenzo Bagnolo, Raffaele Argiolas and Cristina Vanini compare their 3D laser scanner survey of the vaults of the church of Santa Lucia with descriptions in historic treatises, to evaluate which of the theoretical models proposed in the two treatises best approximates the reality, and then conduct algorithmic modelling of the surface closest to the geometry of the vaults revealed by the point cloud.

The Brazilian team of Caio Castriotto, Gabriela Celani and Filipe Tavares. "Reciprocal Frames Algorithm based on Symmetry Groups" address the difficulties of applying reciprocal frame structures to complex surfaces. They do this with a new approach to represent RF geometry, based on symmetry theory, combining pinwheel patterns with wallpaper symmetry groups.

In the Didactics section of this issue, the Portuguese team of Orkan Zeynel Güzelci, José Pedro Sousa and João Pedro Xavier present "Integrated Structural and Environmental Form-Finding: A Teaching Experiment", in which students are able to compare earlier analog and digital procedures to today's 3D digital computational models while they explore the integration of formal, structural, and environmental performance criteria in design. 
While the contributions presented up to here involve contemporary architecture, the three contributions presented next involve the task of interpreting great architecture of the past. The oldest of these, the King's Chamber of the Great Pyramid, still presents unexplained elements. In "Determining if the Offset of the Niche Predicts the Offset of the King's Chamber", Kyle Weyburne demonstrates a mathematical correlation between the offset of the Niche in the Queen's Chamber and the offset of the King's Chamber, raising the possibility that the southerly offset of the one predicts that of the other.

Antonis Katsarakis, in "The Architectural Grid of Ibrahim Han Mosque in Réthymnon, Crete", a structure of the mid-seventeenth century, combines a geometrical device to govern architectural planning with a metrical investigation; he uses the application of a grid as a case study for detecting the historical ell values used in the island.

Nelly Shafik Ramzy, in "Beyond Beauty, Life and Nature in the Geometry of Nasir El-Molk Mosque in Iran" employs Christopher Alexander's properties of art and nature and a numerical model by Nikos Salingaros in order to carry out a qualitative analysis of the visual properties of the nineteenth-century Nasir El-Molk mosque.

This issue concludes with two book reviews. In "Formulations: A New Lens on a Colourful Cast Bringing Maths to Mid-Twentieth-Century Architecture" Jane Burry reflects on the book by Andrew Witt, whose article with Iman Fayyad on the double staircase is also in this issue. Finally, in "Architectural Form-Finding through Parametric Geometry" Alberto Lastra offers insights into his own new book, Parametric Geometry of Curves and Surfaces: Architectural Form-Finding, which is the latest volume in the Springer book series "Mathematics and the Built Environment". This series, directed by Kim Williams and Michael J. Ostwald, the editors-in-chief of the Nexus Network Journal, brings out monograph-length discussions of the themes treated in each issue of our journal.

Publisher's Note Springer Nature remains neutral with regard to jurisdictional claims in published maps and institutional affiliations.

Kim Williams received her degree in Architectural Studies from the University of Texas in Austin. She became interested in mathematics and architecture while writing Italian Pavements: Patterns in Space (Anchorage Press, 1997) about the role of decorated pavements in the history of Italian architecture, and it has been her field of research ever since. She is the founder and director of the international, interdisciplinary conference series "Nexus: Relationships Between Architecture and Mathematics", and is the founder and co-editor-in-chief (with Michael Ostwald) of the Nexus Network Journal. Following her publication of Daniele Barbaro's Vitruvius of 1567 (Birkhäuser, 2019), her latest publication, co-authored with Cosimo Monteleone, is Daniele Barbaro's Perspective of 1568 (Birkhäuser, 2021). 